\title{
INTRAUTERINE GROWTH RESTRICTION : AN UPDATE
}

\section{ABSTRACT}

Intrauterine growth restriction [IUGR] is one of the leading cause of perinatal mortality and morbidity. Antenatal fetal surveillance should be focused to identify intra uterine growth restriction and intervene timely. Screening begins with identifying pregnant women at risk of carrying growth restricted fetuses. Ultrasonic fetal biometry, amniotic fluid volume estimation and Doppler study of fetal blood flow velocity play a valuable role in screening as well as management of IUGR. There is no promising antepartum fetal therapy to correct IUGR. Therefore intensive fetal monitoring, which may be limited by facilities available, is suggested to time the delivery of growth restricted fetuses. Further care in a well equipped neonatal unit by dedicated team of pediatrician and nurses and appropriate follow up of these growth restricted newborns determines the overall outcome.

\section{Key Words: Intrauterine growth restriction, Etiology, Screening, Diagnosis, Management.}

\section{INTRODUCTION}

Intrauterine growth restriction [IUGR] is a condition characterized by failure of a fetus to achieve its intrinsic growth potential. This condition is encountered in $10-15 \%$ of the pregnancies and the perinatal outcome is impaired mainly as a consequence of fetal hypoxemia that is present in $30 \%$ of IUGR fetuses. ${ }^{1}$ In India, IUGR contributes to almost two thirds of low birth weight infants. ${ }^{2}$ It is often confused as synonymous with small for gestational age fetus. SGA is defined as birth weight and or length at least two standard deviations below the mean for gestational age. ${ }^{3}$ Majority of small for date fetuses are constitutionally small but healthy and are not growth restricted. ${ }^{4}$ Majority of children who are SGA achieve catch up growth which is usually completed by the time they are 2 years of age. ${ }^{3}$

Birth weight is the most commonly used method to detect IUGR. Neonates below the 3rd or the 10th percentile for gestation are generally considered as growth restricted.
Common morbidities are more frequently seen in less than 3 rd percentile group as compared to 3 rd to 10 th percentile group. However, fetal growth restriction is best defined postnatally by an index of body mass. SGA/IUGR is a public health problem, since $2.5-3 \%$ of newborns are affected by definition, and $8-10 \%$ of them do not catch up postnatally, presenting with a persistent severe height deficiency, developmental difficulties and poor outcome. ${ }^{6}$ To know the birth weight percentile, accurate assessment of gestational age and tables appropriate for the population adjusted for gender, race and birth order are required. ${ }^{5}$

Detection and timely intervention of IUGR is essential to avoid consequences like intrauterine fetal deaths, neonatal deaths as well as severe neurological handicap and learning disabilities. It is now realized that under nutrition in utero can also lead to morbidities like diabetes mellitus, hypertension and cardiovascular diseases in adult life. ${ }^{7,8,9,10}$ In fact, children with IUGR may be at higher risk of hypertension already in childhood. ${ }^{11}$

Address for correspondence : Dr. Pushpa Chaudhary

Maternity Hospital, Thapathali, Kathmandu, Nepal

Email: deopushpa@wlink.com.np 


\section{ETIOLOGY AND PATHOGENESIS}

Normal fetal growth depends on the genetically predetermined growth potential and its modulation by the health of the fetus, placenta and the mother. ${ }^{12}$ Pathophysiology underlying IUGR are very complex and poorly understood. There are several factors that can lead to reduction in fetal cell size as well as cell number and are broadly categorized as fetal factors (infection, structural and chromosomal abnormalities), maternal factors (medical disorders in pregnancy) e.g. respiratory diseases, anemia, renal disease etc., smoking , alcohol and substance abuse) and utero-placental factors ( abruptio placentae, placenta praevia, placental thrombosis \& infection, chorioamnionitis, placental cysts, antiphospholipid antibody syndrome, maternal vascular diseases eg. connective tissue disorders like systemic lupus erythromatosis, diabetes mellitus, hypertension, pre-eclampsia etc.). Of the many potential underlying processes that may result in IUGR, placental disease is clinically the most relevant. Fetal cardiovascular and behavioral responses to placental insufficiency and the metabolic responses are interrelated. ${ }^{12}$ An impairment in the invasion of fetal trophoblast cells into the maternal decidua has been hypothesized as a cause of placental insufficiency leading to intrauterine growth restriction. ${ }^{13}$ The growth aberration is usually the consequence of inadequate substrates for fetal metabolism and, to a greater or lesser degree, decreased oxygen availability. ${ }^{14}$

It is important to differentiate between early and late onset growth restriction. Late onset growth restriction is that which is detected after 32 weeks gestation and is usually due to uteroplacental dysfunction. Utero-placental dysfunction is defined as a condition when nutrient and oxygen exchange at the maternal-fetal interface is inadequate to support normal growth and aerobic metabolism in the foetus. ${ }^{5}$ Early onset growth restriction is detected before 32 weeks and is often associated with fetal abnormalities, fetal infection and severe uteroplacental dysfunction.

\section{SCREENING FOR IUGR}

Antenatal fetal surveillance involves detection of congenital malformation in the first half of pregnancy, screening for fetuses at risk of growth restriction and assessment of fetal well being and growth in later half of pregnancy. Smoker mothers, history of substance abuse, underweight mothers $($ BMI $<19)$, history of previous IUGR and unexplained stillbirths, mother known to suffer from vascular diseases like systemic lupus erythromatosis etc. are potential candidates to carry fetus likely to suffer from IUGR.
Biochemical screening, most commonly used in western countries is the estimation of maternal serum a-fetoprotein at approximately 16 weeks gestation which is a marker of abnormal placentation. ${ }^{15}$ Clinically, measurement of fundal height for detection of IUGR is the most commonly used screening method (Sensitivity - 60-85\%, positive predictive value $(20-80 \%)$. Though very limited trial information is available to support fundal height measurement as a good screening test, ${ }^{4}$ it enhances the accuracy of sonographic assessment. Similarly, traditional use of repeated maternal weight check-up has not been proved by evidence as a good predictor of IUGR. ${ }^{16}$

Ultrasound is the mainstay of screening for IUGR and evaluation for fetal growth. This is based on fetal biometry, percentile rank of the measurement for appropriate gestational age, interval growth since last study, amniotic fluid volume measurement and Doppler measured flow velocity of fetal arterial and venous circulation. Fetal growth assessment requires accurate estimation of gestational age, and serial studies, rather than a single ultrasonic assessment.

Abdominal circumference (AC) measurement best reflects fetal nutrition and among all growth parameters has both highest sensitivity and negative predictive value for sonographic diagnosis of IUGR..$^{17}$ The most accurate AC is the smallest obtained at the level of the hepatic vein. If a table based on healthy women delivering appropriately nourished fetuses at term is used, an $\mathrm{AC}<2.5$ percentile for gestation age is consistent with IUGR. 10th percentile cut off is appropriate if table is based on population including preterm and small for gestational age fetuses. ${ }^{5}$ If possible IUGR is detected, additional growth studies are needed at 2-3 weeks interval. The positive predictive value of a low $\mathrm{AC}$ percentile for growth restriction is about $50 \%$ in any given population.

Clinical utility of fetal weight estimation by ultrasound is controversial as it lacks precision. ${ }^{18}$ In general, the accuracy of fetal weight estimation by ultrasound is $? 10 \%[ \pm 2 \mathrm{SD}]$. However, Intensive fetal surveillance should be triggered if $\mathrm{AC}$ is far below normal and other parameters like estimated fetal weight is also subnormal. Application of a three dimensional ultrasound method for estimation of fetal weight promises better precision. ${ }^{19}$

Doppler studies if available is an useful adjunct to the management of IUGR and prediction of fetal hypoxaemia. ${ }^{20}$ Since the introduction of Doppler ultrasound, the problems associated with screening, diagnosing, monitoring, and identifying and identifying fetuses have decreased in recent 
years. ${ }^{21}$ Uterine artery Doppler studies has been tried for screening for IUGR but not proven to be cost effective. Uterine artery Doppler at 11-14 weeks of gestation identifies a high proportion of women who develop severe preeclampsia and or fetal growth restriction. ${ }^{22,23}$ Elevated resistance index at 20 weeks was significantly associated with IUGR but the correlation was not found close enough to be clinically useful as a screening test. ${ }^{24}$ Persistence of an early diastolic notch in the uterine artery beyond 24 weeks gestation increases the risk of IUGR or pre-eclampsia. ${ }^{25,26,27,28,29,30}$ In uteroplacental dysfunction, there is initially increased resistance in the umbilical artery, followed by decreased resistance in the middle cerebral artery signifying cephalisation of blood flow due to redistribution of cardiac output and preferential perfusion of brain and myocardium. If hypoxemia is not corrected, abnormal venous flow develops as cardiac activity deteriorates..$^{25}$

\section{DIAGNOSIS AND MANAGEMENT}

When fetus at risk of IUGR is identified on clinical or sonographic screening, diagnosis is confirmed by serial growth scans. Supplemented with biophysical profile and doppler studies of fetal arterial and venous blood flow, nature of the compromise and deteriorating fetal status can be identified. ${ }^{31}$ In the majority of severely intrauterine growth restricted fetuses, sequential deterioration of arterial and venous flows precedes biophysical profile score deterioration. Adding serial Doppler evaluation of the umbilical artery, middle cerebral artery and ductus venosus to intrauterine growth restriction surveillance will enhance the performance of biophysical score. ${ }^{32,33,34,35}$

For late onset growth restriction, close surveillance include twice weekly amniotic fluid estimation, biophysical profile, doppler studies of fetal arterial and venous circulation if available and 2-3 weekly growth scan if detected before 36 weeks. The goal of antenatal surveillance is to detect the disease status of fetus and to initiate therapeutic intervention at an early stage of compromise in order to minimize morbidity and adverse sequele. Where facilities are limited, surveillance of IUGR fetus is mainly based on fetal movement counting, amniotic fluid volume measurement and non stress test (cardiotocography). Amniotic fluid index estimation should be a part of antenatal fetal surveillance in high risk pregnancies. ${ }^{36}$

Antepartum therapy has been attempted to improve fetal growth and prolong pregnancy, as delivery of very preterm growth restricted fetus is clearly not beneficial. ${ }^{37}$ Factors like stress and smoking should be restricted. Rest in left lateral position is advised to facilitate placental perfusion. Hospitalization and complete bed rest is recommended, though not of proven value, but facilitates fetal monitoring. ${ }^{4}$ Long term oxygen supplementation to the mother to correct fetal hypoxemia is at present considered to be in experimental stage. Low dose aspirin treatment has not been proved to be effective in pregnancies complicated with fetal growth restriction. ${ }^{38}$

Severe early onset growth restriction may necessitate detection of chromosomal abnormality or any fetal infection eg. TORCH infection. Cordocentesis is the best method not only to know blood $\mathrm{pH}$ and $\mathrm{pO} 2$ but also to diagnose chromosomal abnormality or fetal infection. However, facility may not be available and there is inherent procedure related risk in already compromised fetus. Moreover, non invasive tests like biophysical profile and Doppler study of umbilical artery can predict the degree of fetal acidaemia. ${ }^{39,40}$

There is limited scope for treatment of an infected fetus as no effective in utero therapy is available for common viral infection in pregnancy e.g. cytomegalovirus [CMV] infection. Termination of pregnancy can be an option for lethal congenital malformations.

In mild to moderate IUGR, labor should be induced if gestation is $>36$ weeks and cervix is favorable. Severe Oligohydramnios at 36 weeks gestation or more, mandates delivery irrespective of Bishop score of cervix. Delivery should be effected if there is repeated late decelerations on cardiotocography. If the fetus is $>32$ weeks but show no evidence of growth on serial scan, delivery should be considered. Abnormal doppler studies indicative of fetal acidemia also necessitates delivery. A course of corticosteroid is suggested if delivery is preterm. Timing of delivery of a preterm growth restricted fetus can be crucial and requires great clinical acumen. Involvement of pediatrician and the parent is recommended in such a difficult decision making as fetal outcome is very uncertain. Caesarean delivery without a trial of labor is indicated if there is evidence of fetal acidemia.

Lastly, a well equipped neonatal intensive care unit and dedicated pediatric team is essential to look after severely growth restricted fetuses.

\section{CONCLUSION}

Evaluation and management of growth restricted fetuses need a multi disciplinary dedicated team of obstetricians, sonographers, feto-maternal specialist and pediatric team in order to achieve the best perinatal outcome. 


\section{REFERENCES}

1. Mandruzzato G, Meir YJ, Natale R, Maso G. Antepartum assessment of IUGR fetuses. J Perinat Med. 2001; 29 (3) : 222-9.

2. Deorari AK, Aggarwal R, Paul VK. Management of infants with intrauterine growth restriction. Indian J Pediatr. 2001 Dec; $68(12): 1155-7$.

3. Lee PA, Chernausek SD, Hokken-Koelega AC, Czernichow P. International Small for Gestational Age Advisory Board consensus development conference statement : management of short children born small for gestational age, April 24October 1, 2001. Pediatrics. 2003 Jun; 111 (6 pt 1) : 125361.

4. Enkin Murray, Keirse Marc J.N.C, Neilson James, Crowther Caroline, Duley Lelia, Hodnett Ellen, Hofmeyr Justus. Editors A guide to effective care in pregnancy and childbirth [third edition] Oxford $2000: \mathrm{p}-80$.

5. Weiner Carl P., Baschart Ahmet A. Fetal growth restriction: Evolution and management. In James D K, Steer P J, Weiner C P, Gonic B editors. High risk pregnancy: management option [second edition]. 1999 : p-291.

6. Chatelain P. Children bom with intrauterine growth retardation or small for gestational age: long term growth and metabolic consequences. Endocr Regul. 2000 Mar; 34 (1) :33-6.

7. Sallout B, halker M. The fetal origin of adult diseases. JCbstet. Gynecol . 2003 Sept; 23 (5) : 555-60.

8. Szathmari M, Vasarhelyi B, Tulassay T. Correlations of low birth weight and diseases in childhood. The hypothesis, the facts and the doubts Orv Hetil. 2002 Sep 29; 143 (39) : 22218.

9. Wolf G. Adult type 2 diabetes induced by intrauterine growth retardation. Nutr Rev. 2003 May; 61 (5 pt 1) : 176-9.

10. Salle BL, Chatelain $\mathrm{P}$, Nicolino M, Claris O. Intrauterine growth retardation, its consequences in infancy, in the child and long term. Bull Acad Natl Med. 2001; 185 (7) : 1271-6; discussion.

11. Fattal Valevski A, Bernheim J, Leitner Y, Redianu B, Bassan $\mathrm{H}$, Harel S. Blood pressure values in children with intrauterine growth retardation Isr Med AssOC J. 2001 Nov; 3 (11) : 8058.

12. Baschat $\mathrm{AA}$, Hecher $\mathrm{K}$. Fetal growth restriction due to placental disease. Semin perinatol. 2004 Feb; 28 (1) : 67-80.

13. Pardi G, Marconi AM, Cetin I. Placental-fetal interrelationship in IUGR fetuses- a review. Placenta.2002 Apr; 23 Suppl A: S136-41.

14. Resnik R. Intrauterine growth restriction. Obstet Gynecol. 2002 Mar; 99 (3) : 490-6.
15. Yahkowitz Jerome, Williamson Rogen A. Abnormalities of alpha fetoprotein \& other biochemical tests. In James D K, Steer P J, Weiner C P, Gonic B editors. High risk pregnancy: management options [second edition] W.B. Saunders 1999. $\mathrm{p}-155$.

16. Dawes M.G. and Grudzinskas J.G. Repeated measurement of matemal weight during pregnancy. Is this a useful practice? Br. J. Obst. \& Gyn. 1991 98:189.

17. Harding Kate, Evans Sharon and Newnham John. Screening of the small fetus : A study of the relative efficacies of ultrasound biometry and symphysio-fundal height. Aust NZ J obstet-gynaecol 1995; 39: 2 :160.

18. Rogers M.S., Chung T.K.H, Allen M.Z. Ultrasound fetal weight estimation : precision or guess work? Aust NZ J obstetgynaecol 1993; 33:2:142.

19. Marsal K. Intrauterine growth restriction. Curr Opin Obstet. Gynecol 2002 Apr; 14 (2) : 127-35.

20. Chang T.C., Chang H.H. Recent advances in the use of Doppler waveform indices in the antenatal assessment of intrauterine growth retardation. Aust NZ J obstet-gynaecol 1994; 34:1:8.

21. Leung KY, Liu JYS. Modern management of intrauterine growth retardation. HKMJ 1998; Vol 4: no 1 42-46.

22. Martin AM, Bindra $R$, Curcio $\mathrm{P}$, Cicero $\mathrm{S}$, Nicolaides $\mathrm{KH}$. Screening for preeclampsia and fetal growth restriction by uterine artery Doppler at 11-14 weeks of gestation. Ultrasound Obstet Gynecol. 2001 Dec; 18 (6) : 583-6.

23. Schuchter $\mathrm{K}$, Metzenbauer $\mathrm{M}$, Hafner $\mathrm{E}$, Philipp K. Uterine artery Doppler and placental volume in the first trimester in the prediction of pregnancy complications. Ultrasound obstet. Gynecol. 2001 Dec; 18 (6) : 590-2.

24. Jacobson Sig-Linda, Imhof Regine, Manning Nick, Mannion Vibeke, Little David, Rey Evelyn, Rechan Christopher. The value of Doppler assessment of the utero-placental circulation in predicting pre-eclampsia or intrauterine growth retardation. Aust J. obstet-gynaecol 1990; 162:110-4.

25. Malcus Peter. The role of Doppler ultrasound in high risk pregnancies. In Arulkumaran S., Ng Soon-chye editors. current issues in obstet \& gynaecol. Oxford univ. press, Singapore. $2000 \mathrm{p}-215$.

26. Fay Roger A., .Ellword David A, Bruce Suzanne, Turner Anne. Color doppler imaging of the utero-placental circulation in the mid-trimester: Features of the uterine artery flow velocity waveform that predict abnormal pregnancy outcome. Aust NZ J obstet-gynaecol 1994; 34: 5:515.

27. Phupong V, Dejthevaporn $\mathrm{T}$, Tanawattanacharoen $\mathrm{S}$, Manotaya S, Tannirandorn Y, Charoenvidhya D. Predicting the risk of preeclampsia and small for gestational age infants by 
uterine artery Doppler in low risk women. Arch Gynecol Obstet. 2003 Aug; 268 (3) : 158-61. Epub.

28. Missfelder-Lobos H, Teran E, Lees C, Albaiges G, Nicolaides $\mathrm{KH}$. Platelet changes and subsequent development of preeclampsia and fetal growth restriction in women with abnormal uterine artery Doppler screening. Ultrasound Obstet. Gynecol. 2002 May; 19(5) : 443-8.

29. Coleman MA, McCowan IM, North RA. Mid-trimester uterine artery Doppler screening as a predictor of adverse pregnancy outcome in high risk women. Ultrasound Obstet Gynecol. 2000 Jan; 15 (1) : 4-6

30. Papageorghiou AT, Yu CK, Cicero S, Bower S, Nicolaides KH. Second trimester uterine artery Doppler screening in unselected populations : a review. JMatern Fetal Neonatal Med. 2002 Aug; 12 (2) : 78-88.

31. Baschat AA, Harman CR. Antenatal assessment of the growth restricted fetus. Curr Opin Obstet Gynecol. 2001 Apr; 13 (2) : 161-8.

32. Mandruzzato GP, Meir YJ, Maso G, Conoscenti G, Rustico MA. Monitoring of the IUGR fetus. J Perinat Med. 2003; 31 (5) : 399-407.

33. Baschat AA, Gembruch U, Harman CR. The sequence of changes in Doppler and biophysical parameters as severe fetal growth restriction worsens. Ultrasound Obstet Gynecol. 2001 Dec; $18(6): 571-7$.

34. Seyam YS, Al-Mahmeid MS, Al-Tamimi HK. Umbilical artery Doppler flow velocimetry in intrauterine growth restriction and its relation to perinatal outcome. Int J Gynecol Obstet. 2002 May; $77(2): 131-7$.

35. Baschat AA. Doppler application in the delivery timing of the preterm growth restricted fetus: another step in the right direction. Ultrasound Obstet Gynecol. 2004 Feb; 23 (2) : 1118.

36. Anandkumar C., Biswas A, Arulkumarum S., Wong Y.C., Malarwisky G., Ratnum S.S. Should assessment of amniotic fluid volume form an integral part of antenatal fetal surveillance of high risk pregnancy? Aust NZ J obstet-gynaecol 1993; 33: 3: 272 .

37. Lin Chin-chu and Forgas Joaquin Santolaya Current concepts of fetal growth restriction: part 2. [Diagnosis and management]. Obstet-gynaecol 1999; 93:140-144.

38. Newnham John P., Godfrey Maryellen, Walters B.J.N., Phillips John, Evans Sharon F. Low dose aspirin for the treatment of fetal growth restriction: A randomized controlled trial. Aust. NZ J Obst Gynaecol. 1995: 35: 4: 370.

39. Donner Catherine, Vermeylen Danielle, Kirkpatric Christine, Maertelaer Viviane de, Rodesch Frederic Management of the growth restricted fetus : The role of non invasive tests and fetal blood sampling. Obstet-gynaecol 1995; 85: 965-70.

40. Ribbert S.M., Snigders R.J.M., Nicolaides K.H., Visser H.A. Relationship of fetal biophysical profile and blood gas values at cordocentesis in severely growth retarded fetuses. Am. J obstet-gynaecol 1990;163:569-71. 